\title{
EDUCAÇÃO FÍSICA NOS ANOS INICIAIS DO ENSINO FUNDAMENTAL: SIGNIFICAÇÕES DE UMA PROFESSORA
}

\author{
Leonardo Marcelino Luz, Secretaria de Educação Estadual de São Paulo - SEE/SP, São \\ Paulo - Brasil \\ Kresley Neri Magalhães, Prefeitura Municipal de São Paulo - PMSP, São Paulo - Brasil
}

\section{RESUMO}

O objetivo deste artigo é avaliar o papel desempenhado pelo componente curricular Educação Física nos anos iniciais do ensino fundamental, tendo em vista que as aulas para esse segmento da educação básica se deram há poucos anos e há carência de trabalhos acadêmicos sobre o assunto. Para tanto, entrevistamos 01 (uma) professora de Educação Física da rede de ensino pública estadual de São Paulo para analisar e interpretar suas significações a respeito do seu trabalho desenvolvido com os estudantes dos anos iniciais para qual leciona. A análise e interpretação dos dados apontam que a professora busca legitimar a Educação Física neste segmento da educação básica por meio de prováveis contribuições que possa oferecer à professora polivalente, possivelmente devido à sua recente inserção nas escolas e sua frágil história nas escolas dos anos iniciais do ensino fundamental. Discute-se ao final qual seria o papel da Educação Física como componente curricular nos anos iniciais do ensino fundamental.

Palavras-Chave: Educação Física Eescolar; Currículo; Sentidos e significados.

\section{PHYSICAL EDUCATION IN THE EARLY YEARS OF ELEMENTARY SCHOOL: MEANINGS OF A TEACHER}

\begin{abstract}
The purpose of this article is to evaluate the role played of the Physical Education curriculum component in the early elementary school years, considering that the classes for this segment of basic education was made a few years ago and there is a lack of scholarly work on the subject. To that end, we interviewed one (01) Physical Education teacher network of state public schools in São Paulo to analyze and interpret their meanings about their work with students in the early years for which she teaches. The analysis and interpretation of data indicate that the teacher seeks to legitimize Physical Education in this segment of basic education through probable contributions that can offer the versatile teacher, possibly due to its recent inclusion in schools and his fragile history in schools in the early years of elementary school. It discusses the end what is the role of physical education as a curriculum component in the early years of elementary school.
\end{abstract}

Key-Words: School Physical Education; Curriculum; Senses and meanings. 


\title{
LA EDUCACIÓN FÍSICA EN LOS PRIMEROS AÑOS DE LA ESCUELA PRIMARIA: SIGNIFICADOS DE UN MAESTRO
}

\begin{abstract}
RESUMEN
El propósito de este artículo es evaluar el papel desempeñado del componente curricular de Educación Física en los primeros años de la escuela primaria, ya que las clases para este segmento de la educación básica se ha realizado hace unos años y hay una falta de trabajos académicos sobre el tema. Para ello, entrevistamos a uno (01) de red profesor de Educación Física de las escuelas públicas del Estado de São Paulo para analizar e interpretar sus significados sobre su trabajo con los estudiantes en los primeros años de los que él enseña. El análisis e interpretación de los datos indican que el maestro busca legitimar la Educación Física en este segmento de la educación básica a través de las probables contribuciones que puede ofrecer el profesor versátil, posiblemente debido a su reciente inclusión en las escuelas y su historia frágil en las escuelas, en los primeros años de la escuela primaria. Discute el final lo que es el papel de la educación física como un componente curricular en los primeros años de la escuela primaria.
\end{abstract}

Palabras-Clave: Escuela de Educación Física; Plan de estudios; Sentidos y significados. 


\section{INTRODUÇÃO}

A história da Educação Física como componente curricular dos anos iniciais do ensino fundamental nas escolas da rede de ensino pública estadual paulista remonta a um período recente quando comparada à própria história da Educação Física Escolar. Sua sistematização se inicia mais consistentemente com a criação do ciclo básico (CB), criado durante o governo de André Franco Montoro (1983-1986).

No entanto, sucessivas dificuldades fizeram com que sua retirada da grade curricular se desse no ano de 1995, no governo de Mário Covas. De acordo com Bonel ${ }^{1}$ ocorreram discordâncias entre os professores especialistas e os gestores escolares, e também problemas na formação dos professores, que ainda tinham uma visão de Educação Física Escolar essencialmente esportivista.

Há outra teoria defendida por Lippi e Lima ${ }^{2}$ de que a retirada da Educação Física se deu por motivos econômicos: se na escola já existe a figura da professora polivalente, que leciona diversos componentes curriculares e que tem a Educação Física em sua formação inicial, não haveria porque manter mais um professor apenas para lecionar um único componente curricular.

Seja como for, a verdade é que a Educação Física como componente curricular nos anos iniciais da escolarização padecia de uma concepção que a enfraquecia, por um lado devido a uma visão idealizada de infância como um período em que a criança descobre naturalmente seu corpo e constitui sua motricidade; por outro lado porque os próprios profissionais da área pareciam não ter a suficiente disposição e interesse por esse segmento da educação básica.

Os dados apurados por Silva ${ }^{3}$ sintetizam bem o que queremos dizer. Em sua pesquisa documental do período compreendido entre os anos de 1983 e 2002, a autora chegou à seguinte conclusão:

os documentos analisados criticamente permitiram-nos concluir que esse conjunto de medidas tomadas nesses quase vinte anos (1983-2002) para as primeiras séries do Ensino Fundamental da rede pública estadual não favoreceu a efetivação da Educação Física junto a esse nível de ensino. ${ }^{3: 178}$

Conexões: revista da Faculdade de Educação Física da UNICAMP, Campinas, v. 13, n. 2, p. 168-184, abr./jun. 2015. ISSN: $1983-9030$ 
Dessa forma, é plausível considerar que no Ciclo Básico a experiência da Educação Física para as crianças da então $1^{\text {a }}$ a $4^{\text {a }}$ série foi quase insuficiente. E talvez por isso que, de 1995 a 2002, as crianças de $1^{\mathrm{a}}$ a $4^{\mathrm{a}}$ série do ensino fundamental - hoje do $1^{\mathrm{o}}$ ao $5^{\mathrm{o}}$ ano - não tiveram aulas de Educação Física com um professor especialista.

Essa situação começou a ser mudada a partir do ano de 2002, quando foram realizados dois fóruns na Assembleia Legislativa do Estado de São Paulo para tratar do tema. Esses fóruns contaram com a presença de pesquisadores acadêmicos, representantes da sociedade civil, das diretorias de ensino vinculados à Secretaria Estadual de Educação de São Paulo (SEE/SP) e de alguns professores de Educação Física. No fim daquele ano, em 28 de dezembro, foi publicada a resolução $\mathrm{n}^{\circ} 184$, que estabeleceu o retorno das aulas de Educação Física para o professor especialista da área nas escolas da rede pública estadual com os cinco anos iniciais do ensino fundamental. Portanto, estamos apenas há pouco mais de 11 (onze) anos com aulas neste segmento, um período relativamente curto frente à história da área.

Esse breve período, no entanto, enseja a oportunidade de pesquisas que podem contribuir para os estudos da área, inclusive em pesquisas que possam se reverter em benefício para o próprio professor que está na sala de aula com os estudantes.

Pensando nisso é que resolvemos investigar quais os Sentidos e os Significados que uma professora constitui sobre seu trabalho nos anos iniciais do ensino fundamental.

\section{APORTE TEÓRICO}

De acordo com Vigotski ${ }^{4}$ os Sentidos e Significados são categorias que ajudam a compreender o Pensamento e a Linguagem dos sujeitos em uma relação que é, simultaneamente, mediada, contraditória e dialética. Enquanto os Significados são mais dicionarizados - e por essa característica, compartilháveis -, os Sentidos dizem mais respeito à dimensão subjetiva da cada sujeito, sendo por isso mais individualizada. Assim, para acessar os Sentidos e os Significados a entrevista é o meio que entendemos ser o mais apropriado para termos acesso às Significações constituídas pela nossa entrevistada.

Conexões: revista da Faculdade de Educação Física da UNICAMP, Campinas, v. 13, n. 2, p. 168-184, abr./jun. 2015. ISSN: 1983-9030 
Embora sejam constituintes do Pensamento e da Linguagem de maneira dialética, é possível diferenciar os Sentidos dos Significados. Os Significados são significações que podem ser expressas de maneira coletiva, ainda que de forma indireta, como por meio de um questionário ou grupo focal, por exemplo. Porém, se o intuito for apreender os Sentidos, a entrevista individualizada é o meio mais apropriado para sua obtenção.

Os Sentidos dizem respeito à dimensão subjetiva de cada sujeito. Quando estamos em um grupo de professores e os indagamos sobre os motivos que os levaram a optar pela docência podemos ouvir respostas referentes à uma mãe que era professora; à brincadeiras infantis, ou ainda a um (a) professor (a) da educação básica que serviu de inspiração. No entanto, se quisermos nos aprofundar, por exemplo, na resposta do primeiro entrevistado, devemos procurar intensificar as maneiras de acessar seus Sentidos: quem era sua mãe? Que componente curricular lecionava? Até que ponto sua convivência a levou a optar pela mesma profissão?

Em síntese, quando procuramos acessar os Sentidos de um sujeito, estamos em busca de significações que apenas ele pôde constituir ao longo de sua história de vida até aquele momento. Em nosso caso, estamos falando sobre a profissão docente.

\section{MÉTODOS}

O objetivo da pesquisa consistiu em apreender, analisar e interpretar os Sentidos e Significados de uma professora de Educação Física sobre o seu trabalho realizado em uma unidade escolar de ciclo I e II (os cinco anos iniciais do ensino fundamental) da rede de ensino pública estadual paulista.

Consideramos que as significações são historicamente constituídas no meio social em que o sujeito se encontra inseridas. Por tal característica as significações, ainda que individuais, trazem consigo a totalidade, isto é, uma significação de um único sujeito pode nos ajudar a desvelar algo maior, como sua formação profissional, seu convívio entre pares etc.

Conexões: revista da Faculdade de Educação Física da UNICAMP, Campinas, v. 13, n. 2, p. 168-184, abr./jun. 2015. ISSN: 1983-9030 
Realizamos duas entrevistas entre outubro de 2011 e agosto de 2012 com uma professora de Educação Física que leciona para os anos iniciais do ensino fundamental. Isabel ${ }^{1}$ graduou-se em Educação Física por uma universidade pública de São Paulo em 1982, e no ano de 1990 ingressou por concurso público na rede de ensino pública estadual paulista. Desde o ano de 2004 passou a lecionar para o ciclo $\mathrm{I}^{2}$, os cinco anos iniciais do ensino fundamental, nas escolas da rede de ensino pública estadual paulista.

De posse das transcrições das falas, passamos a elaborar os Núcleos de Significação (NS), com base em método proposto por Aguiar e Ozella. ${ }^{5}$ Para chegar a um NS percorre-se primeiro à seleção das falas do sujeito que tem a ver com nosso objetivo da pesquisa, e que chamamos de Pré-Indicadores. Em segundo lugar aglutinam-se essas falas em Indicadores, que são reunidos pelos critérios no que as falas têm de similar, de complementar ou ainda de contraposição. Dois ou mais Indicadores formam um NS.

Em nossa pesquisa chegamos à elaboração do NS que nominamos como Concepção de aluno e do processo de ensino e aprendizagem, que contém o Indicador que aqui será analisado, As aulas e os alunos do ciclo $I$.

\section{RESULTADOS}

Analisando e interpretando os Sentidos e Significados da entrevistada procuramos em primeiro lugar saber suas significações a respeito de seu trabalho com a professora de educação básica I, a professora polivalente. Essa parte da entrevista é importante na medida em que pode nos revelar uma faceta do trabalho do professor de Educação Física que só ocorre neste ciclo de escolarização, já que a partir do 6o ano os estudantes têm professores especialistas para cada componente curricular. Nas unidades escolares da rede de ensino pública estadual paulista com os cinco anos iniciais do ensino fundamental os estudantes só têm aula com dois professores além da professora polivalente: o professor de Artes e o professor de Educação Física.

\footnotetext{
${ }^{1}$ Nome fictício.

${ }^{2}$ No início do ano letivo de 2014 a Secretaria Estadual de Educação de São Paulo (SEElSP) promoveu uma alteração no sistema de ciclos de sua rede de ensino: o ciclo I corresponde agora do $1^{\circ}$ ao $3^{\circ}$ ano; o ciclo II compreende do $4{ }^{\circ}$ ao $6^{\circ}$ ano; e o ciclo III do $7^{\circ}$ ao $9^{\circ}$ ano.

Conexões: revista da Faculdade de Educação Física da UNICAMP, Campinas, v. 13, n. 2, p. 168-184, abr./jun. 2015. ISSN: $1983-9030$
} 
Antes da entrada do professor de Educação Física no ano de 2003, a professora polivalente era a única profissional que mantinha contato com os estudantes, desde a então primeira série até a quarta série. Com a inserção de Artes e Educação Física na grade curricular, essa situação se modificou e causou repercussões tanto para a professora polivalente quanto para os professores especialistas.

Isabel observa essa relação e a expressou da seguinte forma:

"Porque na realidade no ciclo um você tem um professor para cada sala de aula, ele [aluno] tem uma identidade (...) quando chega no ciclo dois eles ficam meio que jogados (Professora Isabel)."

Isabel fala com conhecimento de causa, já que antes de trabalhar com o ciclo I havia lecionado para estudantes de ciclo III e ensino médio, e de certa maneira revela que há uma relação de maior proximidade entre os estudantes e a professora polivalente, que não ocorre quando os estudantes passam a ter aulas com os professores especialistas.

Sobre a relação entre professor de Educação Física e professora polivalente, Brito ${ }^{6}$ observou em sua pesquisa em escolas do município de São Paulo que nem sempre elas são bem resolvidas e administradas. Pela legislação das escolas estaduais de São Paulo, as aulas de Educação Física devem ser "acompanhadas" pela professora regente, a professora polivalente. No entanto, esse acompanhar não é bem caracterizado, e na prática ocorre é que, na maioria das unidades escolares, a professora polivalente não acompanha o professor de Educação Física e os seus estudantes em aulas.

Pensamos que a ideia de acompanhar as aulas possa ter o intuito de fazer com que a professora polivalente possa vir a ter uma visão mais ampla de seus estudantes, já que as aulas de Educação Física ensejam outras demandas que podem ser diferentes da sala de aula a que os estudantes estão costumeiramente habituados. Há casos de estudantes que são rotulados pelas professoras polivalentes como indisciplinados, por exemplo, que se mostram interessados e participativos nas aulas de Educação Física. Isabel expressa essa ideia ao nos revelar a seguinte significação:

Conexões: revista da Faculdade de Educação Física da UNICAMP, Campinas, v. 13, n. 2, p. 168-184, abr./jun. 2015. ISSN: 1983-9030 
“Porque os alunos bonzinhos não aprontam, mas normalmente eles não são muito bons de quadra (...) tem um ou outro que é exceção, mas os mais danados são os bons de quadra (Professora Isabel).”

Essa fala nos sugere haver uma hierarquização de saberes que são mais valorizados na educação escolar em detrimento de outros. Uma rápida constatação de tal fato é comparar o número de aulas semanais dos componentes curriculares de Língua Portuguesa e Matemática com a Educação Física para saber que esta tem menos aulas semanais que aquelas, o que já denota haver uma valorização de saberes na escola. Não é incomum que o professor de Educação Física tenha entre seus alunos alguns com más notas em suas avaliações justamente aqueles que possuem conceitos positivos em componentes curriculares mais valorizados pela educação escolarizada.

Quanto ao seu relacionamento com as professoras polivalentes, Isabel o significou de maneira positiva. Ela nos relatou uma situação em que estava implantando aulas de xadrez e foi uma professora polivalente quem a ajudou, pois tinha pouca experiência com o tema:

"E aí ela foi me dando ideias, ela me deu algumas dicas de como tinha uma história do xadrez, ela me embasou algumas coisas que eu achei legal de começar no [nome da escola] que era bem nível ciclo I (...) Aí, ideia de uma: eu não sabia muito bem como fazer os tabuleiros de xadrez. Aí vinham nas caixas de merenda os tabuleiros de xadrez (Professora Isabel)."

Isabel também nos revelou que procura fazer uma "parceria" com a professora polivalente em algumas ocasiões, como o exemplo que tiramos do seguinte excerto:

\footnotetext{
“eu usei com o $1^{\circ}$ ano que era uma brincadeira de tampinhas e que na realidade era só ir e buscar, tal. E que eu trabalhei em parceria com a professora que estava trabalhando múltiplos no $3^{\circ}$ ano. Então, na realidade, eles tinham que ir buscar a tampinha, juntar lá - estafeta mesmo - então um ia lá, juntava a tampinha e tal. E depois iam ter que contar. Então, na realidade eu usei a habilidade motora de correr, a parte de organização deles, tal, mas, eu usei também a parte de dentro da sala de aula que era contar as tampinha. então o grupo só ia ganhar se contasse o número de tampinhas certo. Para o $1^{o}$ ano. Para o $3^{\circ}$ ano eles tinham que separar em múltiplos, e fazer a conta ali (Professora Isabel).”
}

Essa atividade de estafeta usada por Isabel nos sugere que ela teve outro propósito que, em sua maneira de significar, iria além da atividade motora em si. A atividade deveria auxiliar Conexões: revista da Faculdade de Educação Física da UNICAMP, Campinas, v. 13, n. 2, p. 168-184, abr./jun. 2015. ISSN: 1983-9030 
a compreensão de uma habilidade matemática, que a professora polivalente estava na época ensinando em sua sala de aula.

A justificativa de Isabel é assim por ela expressa:

"E aí, o que acontece? Você ganha o respeito do professor da sala de aula. Então você não é somente o professor de habilidades motoras: você é um professor que está casando conhecimento em sala de aula com atividade física (Professora Isabel).”

A significação expressa em "você ganha o respeito da professora" parece querer dizer que há uma busca da professora em legitimar a Educação Física dentro da escola. Pensamos também que essa fala de Isabel possa guardar relações com o movimento de renovação da Educação Física Escolar que ocorreu entre os anos de 1980 e 1990, já que é nesse período que se deu sua formação inicial e seu ingresso na rede de ensino pública estadual paulista. Esse período compreendido foi profícuo não apenas para a crítica sobre o que era feito nas escolas, bem como para o surgimento de novas abordagens, como exposto por Darido. ${ }^{7}$

Nesse período histórico uma obra que parece guardar relações com a fala de Isabel é Educação de Corpo Inteiro, publicada em primeira edição em formato de livro no ano de 1989. Essa obra do professor João Batista Freire da Silva constaria da edição de muitos concursos públicos para o provimento do cargo de professor. Vejamos como Freire ${ }^{8}$ se posiciona sobre a Educação Física auxiliar outras aprendizagens:

\footnotetext{
Porém, todo conhecimento adquirido serve de base para um próximo, mais elaborado. Sendo assim, uma vez que se tenha um bom domínio de alguma habilidade, pode-se combiná-la com ensinamentos da sala de aula, como leitura, escrita e cálculo. $8: 188$
}

A obra de Freire $^{8}$ além de buscar embasamento teórico na epistemologia genética de orientação piagetiana, também é influenciada pelo psicomotricista francês Jean Le Boulch. Analisamos também trechos da obra de Le Boulch ${ }^{9}$ que reforçam nossa hipótese de que Isabel pode ter sido indiretamente atingida pelo discurso de a Educação Física servir como meio de aprendizagem de outros conteúdos: "Esta passagem, do significante ao significado e inversamente, corresponde ao jogo da função simbólica; não é uma função psicomotora propriamente dita, mas pode ser treinada e educada durante a atividade psicomotora". 9:32 Conexões: revista da Faculdade de Educação Física da UNICAMP, Campinas, v. 13, n. 2, p. 168-184, abr./jun. 2015. ISSN: 1983-9030 
Entretanto, pensamos que não é a intenção de Freire $^{8}$ que a aula de Educação Física seja subordinada às necessidades de leitura, escrita e cálculo tão prementes nos cinco anos iniciais do ensino fundamental. Parece-nos, contudo, que pesquisadores de outras áreas tenham atribuído erroneamente essa característica à Educação Física Escolar nos anos iniciais.

Para tanto, entendemos que Silva ${ }^{3: 131-132}$ tenha conseguido captar bem a essência dessa ideia ao afirmar que "o importante papel da educação física seria então o de promover essa relação concreta sujeito-mundo, partindo dos jogos e brincadeiras propiciadores da evolução dos domínios dos corpos dos alunos".

Entretanto, mais adiante Silva $^{3}$ tratará de fazer sua própria crítica a esse modo de se conceber a Educação Física Escolar nos anos iniciais do ensino fundamental.

Assim, pensamos que o momento político-epistemológico que vivia a Educação Física na época da formação inicial de Isabel e seu ingresso no magistério (ano de 1990) pode tê-la feito travar contato, mesmo que indireto, com essas obras, o que ajudaria a compreender a origem de suas significações sobre o papel da Educação Física nos anos iniciais.

Porém, não seria suficiente nos deter sobre a fala de Isabel para fazer essas conjecturas sobre suas ideias pedagógicas, de modo que resolvemos também analisar os documentos elaborados pela SEE/SP para aumentar nossa compreensão sobre a Educação Física Escolar desse importante período histórico. Encontramos na documentação da extinta Coordenadoria de Estudos e Normas Pedagógicas, ${ }^{1}$ hoje renomeada como Coordenadoria de Gestão da Educação Básica (CGEB) evidências que ajudam a atestar o papel de auxiliar que a Educação Física Escolar deveria desempenhar.

Vejamos como era caracterizada a Educação Física nos anos iniciais pela Secretaria Estadual de Educação de São Paulo:

A Educação Física do Ciclo Básico, até a $4^{\mathrm{a}}$ série do ensino do $1^{\circ} \mathrm{Grau}$, deve ter caráter recreativo, social e formativo, baseada em experiências reais da criança, quando se resgatam os brinquedos e jogos da cultura popular, ou se trabalha em auxílio às outras disciplinas. ${ }^{10}$

Conexões: revista da Faculdade de Educação Física da UNICAMP, Campinas, v. 13, n. 2, p. 168-184, abr./jun. 2015. ISSN: 1983-9030 
Desse modo, pensamos que a passagem "trabalha em auxílio às outras disciplinas" nos faz entender que não é recente a ideia de que as atividades corporais e lúdicas ministradas nas aulas de Educação Física possam servir como um meio para outros fins, como se pôde constatar posteriormente em obras como a de Rosa e Di Nisio, ${ }^{11}$ Mattos e Neira ${ }^{12}$ ou ainda Tisi. $^{13}$

Concordamos, assim, com $\operatorname{Kosik}^{14}$ na história como tri-dimensionalidade: passado e presente mantém uma relação dialética, que ajuda a fazer prognósticos para o futuro. Nessa perspectiva o passado da Educação Física não pode ser visto como cristalizado, congelado no tempo e no espaço, desarticulado do que ocorre no presente. Assim é que nos parece que Isabel constitui seus conhecimentos pedagógicos sobre o papel da Educação Física Escolar nos anos iniciais do ensino fundamental. A história de vida dos sujeitos se torna, assim, um meio de aumentar nossa compreensão sobre suas práticas atuais.

Em outro excerto Isabel revela que trabalhou um conteúdo a partir do que a professora polivalente estava fazendo em sala de aula. Era o mês de agosto, e a professora polivalente trabalhava o resgate de brincadeiras folclóricas, e Isabel resolve participar:

"como as professoras trabalham esse resgate das brincadeiras folclóricas, eu entrei. Teve uma professora que - você vê que tudo isso são casamentos, né - uma professora chegou para mim e disse: "Isabel, vamos fazer cama-de-gato?". Eu falei: "Vamos, mas o que é cama-de-gato?”. Eu nem sabia. É o que eu estou falando: no primeiro ano que eu entrei eu não sabia nada de ciclo I. (Professora Isabel)."

Essa fala de Isabel nos aponta mais uma vez para uma necessidade de busca por justificar e legitimar a presença da Educação Física na escola dos anos iniciais do ensino fundamental, expressa quando ela fala em fazer casamentos com a professora polivalente. Não queremos com isso afirmar que a Educação Física deva estar insensível ao que de resto acontece nas escolas que atendem a essa faixa etária; porém, o que se depreende é que, a despeito de todos os avanços teóricos promovidos dos últimos 30 (trinta) anos em Educação Física Escolar, parece que pouco efeito se faz sentir na prática cotidiana da sala de aula.

Devido ao histórico da Educação Física na experiência anterior do Ciclo Básico ter sido insatisfatória, causando mesmo seu afastamento, Isabel pode com essa atitude de 
cooperação com a professora polivalente também ter a intenção de mostrar uma nova face de seu componente curricular na escola, que consiga apagar aquela experiência frustrada que foi a vivenciada durante o Ciclo Básico.

Sobre o conhecimento que teve que recorrer quando ingressou no magistério, Isabel também nos revelou significações pertinentes que aumenta nossa capacidade de compreensão sobre a Educação Física nos anos iniciais do ensino fundamental. É importante considerar um pouco mais de sua história: Isabel se graduou em uma época (anos 1980) em que ainda não havia sido feita a separação do curso de licenciatura do curso de bacharel.

Graduada, Isabel atuou por 08 (oito) anos em academias e clubes quando, por necessidades de saúde, prestou concurso público e foi aprovada para lecionar na rede de ensino pública do Estado de São Paulo. Segundo nos disse em entrevista, seu interesse não estava direcionado para lecionar em escolas, entretanto, isso não quer dizer que não havia conhecimentos da área:

"Tinha, teve ginástica infantil... tive com o Mauro Guiselini que na época - e acho que até hoje - é um nome importante na área infantil. Lógico, eu curtia a aula dele, mas não era aquela coisa, como aquilo que eu estava te falando, né, de anotar até as vírgulas que ele falasse, porque eu não estava direcionando para aquela área: o foco era a ginástica artística e até competitiva. (Professora Isabel).”

Essa fala nos revela que anteriormente ao período de crítica dos anos 1980 havia conhecimento sobre Educação Física Escolar, mas quando se lê os autores que fazem a crítica a partir do movimento de renovação da Educação Física parece que a história começa com eles. Bracht ${ }^{15}$ também já observara tal fato como um "equívoco", e assim se expressou sobre ele:

o [equívoco] de que o predomínio do conhecimento das ciências naturais, principalmente da biologia e seus derivados, como conhecimento fundamentador da Educação Física, significava a ausência de reflexão pedagógica. Ao contrário [...] até o advento das ciências do esporte nos anos, 70 o teorizar no âmbito da Educação Física era sobretudo de caráter pedagógico [...]. $]^{15: 76-77}$

Conexões: revista da Faculdade de Educação Física da UNICAMP, Campinas, v. 13, n. 2, p. 168-184, abr./jun. 2015. ISSN: $1983-9030$ 


\section{CONSIDERAÇÕES FINAIS}

Pareceu-nos que em suas significações Isabel procura atribuir uma importância à Educação Física como um meio de auxiliar as aprendizagens tidas como mais relevantes pela educação escolarizada: o saber ler, escrever e as operações básicas da matemática.

Também procuramos compreender o movimento de sua constituição como docente, e em tal empreendimento vimos como o momento de sua formação inicial e seu ingresso no magistério coincidiram também com o período de renovação pedagógica da Educação Física, entre os anos de 1980 e início da década de 1990.

É desse período que ganha força a ideia de as atividades corporais/lúdicas sirvam como um meio para aprendizagem de outros conteúdos, primeiro com a Psicomotricidade, cujo autor que mais repercutiu na Educação Física brasileira foi o francês Jean Le Boulch; depois com a obra Educação de corpo inteiro, de João Batista Freire. Na análise dos documentos elaborados pela SEE/SP também foi possível vislumbrar como até a própria CENP se encarregou de atribuir um papel à Educação Física Escolar de "auxiliar outras disciplinas".

Não podemos duvidar que o movimento de renovação pedagógica que a área atravessou foi importante para o seu amadurecimento acadêmico e epistemológico, que conseguiu até mesmo que o retorno das aulas de Educação Física se desse a partir do ano de 2003.

No entanto, pensamos que deve haver hoje a necessidade de depurarmos o que nos foi legado desse importante período para que o professor da escola constitua uma prática pedagógica a serviço dos seus estudantes sem perder de vista o foco em seu objeto de estudo.

Não seria exagero imaginar que, a continuar como está, em breve a Educação Física Escolar e seu professor serão meros acessórios para, supostamente, a aquisição da linguagem falada e escrita nos anos iniciais do ensino fundamental, justamente o período em que a criança precisa exercer sua motricidade de forma sistematizada e bem orientada, ou ainda pior: órgãos centrais podem simplesmente remanejar as aulas desse segmento

Conexões: revista da Faculdade de Educação Física da UNICAMP, Campinas, v. 13, n. 2, p. 168-184, abr./jun. 2015. ISSN: 1983-9030 
para a professora polivalente e promover cursos de capacitação para alfabetização lúdica, o que dispensa a figura de um professor especialista.

Em Minas Gerais a resolução no 253, do ano de 2013, já promulgou que as escolas em que não há professor de Educação Física não terão substitutos ou concurso para preenchimento de vagas, passando a responsabilidade das aulas para a professora polivalente que, em sua maioria, não leciona Educação Física por não se sentir segura com o componente curricular.

É relevante também enfatizar que no Congresso Nacional brasileiro está em apreciação atualmente o Projeto de Lei (PL) no 116/2013 de autoria do deputado Otávio Leite. O referido PL pretende alterar a redação da Lei de Diretrizes e Bases da Educação Nacional no que diz respeito à Educação Física, que passaria a ser obrigatória em toda a educação básica e só poderia ser ministrada por profissionais habilitados na área. Há Estados e Municípios em que a Educação Física não é obrigatória nos anos iniciais do ensino fundamental.

Tal PL já encontra oposição da União Brasileira de Municípios (UBAM), que argumenta que a obrigatoriedade da lei oneraria a folha de pagamento de médios e pequenos municípios, já que teriam que promover concursos públicos para se adequar à lei.

Por um lado entendemos que há um avanço em estender o ensino de Educação Física para os anos iniciais do ensino fundamental; por outro lado não podemos concordar que tal iniciativa seja usada de forma oportunista para que movimentos de defesa da classe profissional (sistemas CREF/CONFEF) com vistas à reserva de mercado. Recordamos que o presidente do CONFEF argumenta que a Educação Física pode ajudar a alfabetização, como uma forma de legitimar sua presença na escola. Entendemos que este tipo de argumentação empobrece o papel do componente curricular e coloca a Educação Física em um papel que não corresponde ao seu objeto de estudo.

Conexões: revista da Faculdade de Educação Física da UNICAMP, Campinas, v. 13, n. 2, p. 168-184, abr./jun. 2015. ISSN: 1983-9030 
Assim, concluímos defendendo que a Educação Física como componente curricular dos anos iniciais possa buscar sua legitimação por sua especificidade, o que beneficiará os estudantes, fim último de um componente curricular. É oportuno recordar que para haver a interdisciplinaridade, é preciso que haja disciplinas que a possa compor e, da forma como ocorre hoje, a Educação Física Escolar nos anos iniciais do ensino fundamental não consegue se sustentar nesse modelo de componente curricular da educação básica. $\mathrm{O}$ desafio parece residir justamente em saber qual a especificidade da Educação Física nos anos iniciais do ensino fundamental.

\section{REFERÊNCIAS}

${ }^{1}$ BONEL, M. M. O ciclo básico: estudo de caso de uma política pública no Estado de São Paulo. 1993. 156 f. Dissertação (Mestrado em Educação) - Faculdade de Educação, Universidade Estadual de Campinas, Campinas, 1993.

${ }^{2}$ LIPPI, B. G.; LIMA, J. M. Professor de Educação Física: a política educacional estadual paulista. Motriz, Rio Claro, v. 12, n. 3, p .249-262, set./dez. 2006.

${ }^{3}$ SILVA, L. F. A trajetória da Educação Física nas primeiras séries do ensino fundamental na rede pública do Estado de São Paulo: entre o proposto e o alcançado. 2002. 201 f. Dissertação (Mestrado em Educação Física) - Faculdade de Educação Física, Universidade Estadual de Campinas, Campinas, 2002.

${ }^{4}$ VIGOTSKI, L. S. A construção do pensamento e da linguagem. São Paulo: Martins Fontes, 2001.

${ }^{5}$ AGUIAR, W. M. J.; OZELLA, S. Apreensão dos sentidos: aprimorando a proposta dos núcleos de significação. Revista Brasileira de Estudos Pedagógicos, Brasília, v. 94, n 236, p. 299-322, jan./abr. 2013.

${ }^{6}$ BRITO, R. G. Relações sócio-profissionais entre o professor regente e o professor de educação física nas séries iniciais: em foco a dimensão afetiva. 2010. 155 f. Dissertação

Conexões: revista da Faculdade de Educação Física da UNICAMP, Campinas, v. 13, n. 2, p. 168-184, abr./jun. 2015. ISSN: 1983-9030 
(Mestrado em Psicologia da Educação) - Pontifícia Universidade Católica de São Paulo, São Paulo, 2010.

${ }^{7}$ DARIDO, S. C. Ação pedagógica do professor de educação física: estudo de um tipo de formação profissional científica. 1997. 283 f. Tese (Doutorado em Psicologia Escolar e do Desenvolvimento Humano) - Instituto de Psicologia, Universidade de São Paulo, São Paulo, 1997.

${ }^{8}$ FREIRE, J. B. Educação de corpo inteiro: teoria e prática da educação física na escola. São Paulo: Scipione, 2001.

${ }^{9}$ LE BOULCH, J. O desenvolvimento psicomotor: do nascimento até os 6 anos. Porto Alegre: Artes Médicas, 1982.

${ }^{10}$ SÃO PAULO (ESTADO). Secretaria da Educação. Resolução SE no 19. Dispõe sobre as aulas de Educação Física no ensino de $1^{\circ}$ e $2^{\circ}$ graus. São Paulo: Secretaria de Educação, 1987. Disponível em: <http://lise.edunet.sp.gov.br/paglei/resolucoes/19_87.htm>. Acesso em: 12 abr. 2012.

${ }^{11}$ ROSA, A. P.; DI NISIO, J. Atividades lúdicas e alfabetização. Curitiba: Juruá, 1999.

${ }^{12}$ MATTOS, M. G.; NEIRA, M. G. Educação física infantil: inter-relações movimento, escrita e leitura. São Paulo: Phorte, 2002.

${ }^{13}$ TISI, L. Educação física e alfabetização. Rio de Janeiro: Sprint, 2004.

${ }^{14}$ KOSIK, K. Dialética do concreto. 2. ed. Rio de Janeiro: Paz e Terra, 1976.

${ }^{15}$ BRACHT, V. A constituição das teorias pedagógicas da Educação Física. Caderno CEDES, Campinas, ano 19, n. 48, p. 69-88, 1999. ISSN: 1983-9030 
Recebido em: 17 out. 2014

Aceito em: 19 mar. 2015

Contato: leo.ef@hotmail.com

Conexões: revista da Faculdade de Educação Física da UNICAMP, Campinas, v. 13, n. 2, p. 168-184, abr./jun. 2015. ISSN: 1983-9030 